\title{
Use of quick response coding to create interactive patient and provider resources.
}

\author{
Jennifer L. Bellot, PhD, RN, CNE
}

Thomas Jefferson University

Kathryn Shaffer, EdD, RN, CNE

Thomas Jefferson University

Mary Wang, MSN, CRNP

Thomas Jefferson University

Follow this and additional works at: https://jdc.jefferson.edu/nursfp

Part of the Nursing Commons

Let us know how access to this document benefits you

\section{Recommended Citation}

Bellot, PhD, RN, CNE, Jennifer L.; Shaffer, EdD, RN, CNE, Kathryn; and Wang, MSN, CRNP, Mary, "Use of quick response coding to create interactive patient and provider resources." (2015). College of Nursing Faculty Papers \& Presentations. Paper 69.

https://jdc.jefferson.edu/nursfp/69

This Article is brought to you for free and open access by the Jefferson Digital Commons. The Jefferson Digital Commons is a service of Thomas Jefferson University's Center for Teaching and Learning (CTL). The Commons is a showcase for Jefferson books and journals, peer-reviewed scholarly publications, unique historical collections from the University archives, and teaching tools. The Jefferson Digital Commons allows researchers and interested readers anywhere in the world to learn about and keep up to date with Jefferson scholarship. This article has been accepted for inclusion in College of Nursing Faculty Papers \& Presentations by an authorized administrator of the Jefferson Digital Commons. For more information, please contact: JeffersonDigitalCommons@jefferson.edu. 
As submitted to:

Journal of Nursing Education

And later published as:

Using QR coding to create interactive patient and provider resources

Volume 54, Number 4, April 2015, pp. 224-7.

DOI: $10.3928 / 01484834-20150318-07$

Jennifer Bellot, PhD, RN, CNE; Kathryn Shaffer, EdD, RN, CNE; and Mary

Wang, MSN, CRNP

\section{Thomas Jefferson University}

Since their development in 1994, Quick Response (QR) codes, also known as 2D codes, have been used for multiple purposes. QR coding was developed in Japan by Denso Wave as a scannable image that could hold up to $20 \%$ more information than a conventional bar code (“Answers to your questions...," n.d.). When a QR code is scanned by a mobile device (Smart phone, phone with camera, tablet, etc.), it prompts the device to open a webpage, link to a video, send a text message, display an image or text and/or make a telephone call. It is, essentially, a "pictographic hyperlink that can be imbedded in the physical environment" (Coleman, 2011, p. 16). The interactive potential of $\mathrm{QR}$ codes makes them an ideal method for patient and provider education. The purpose of this article is to describe a doctoral-level practicum experience for 
nursing students that focused on the creation of patient and/or provider resource guides using QR coding. Application of this practicum has implications in the classroom and in the clinical environment.

\section{QR background and application}

QR coding has seen extensive use in Asia, but less so in Europe or the United States until recently. As QR codes have become more popular in the United States, they have typically been used for marketing purposes, product information and for describing nutritional content in food products. Various industries are now adapting QR use for airline luggage tracking, library science reference coding, asset management, biological specimen collection and identification and video links to enhance scholarly writing (Diazgranados \& Funk, 2013).

The authors searched PubMed and Google Scholar using the terms "QR code," "QR code and health care," "QR code and education" and "2D barcode," limiting results to those printed in English. Since limited examples of QR use in health care or education were located, the authors then searched the popular media using Google. Using this approach, the authors were able to locate additional sources in the format of unpublished documents and conference proceedings.

QR coding has also seen some application in the educational environment, focusing on realtime formative evaluation, student satisfaction and moving the delivery of basic content to more in-depth, student-led inquiry ("Fire department tests...," 2012; Al-Khalifa, 2006; Bonifacio, 2012). One educator created an interactive periodic table of the elements using QR codes to appeal to blind and visually impaired chemistry students (Bonifacio, 2012).

In the health care environment, there is very little scholarly literature about the utility or application of QR coding. A team of researchers in Spain used QR codes to create adaptive 
manuals for daily life activities for patients with acquired brain injuries. Their study found that QR codes were an appropriate technology that encouraged interactivity and individualization to the patient; however, results were severely limited since only one patient tested the intervention (Gomez, Montoro, Haya, Alaman, Alvez \& Martinez, 2013).

In Taiwan, a group of researchers pilot tested the use of $\mathrm{QR}$ coding for patient identification and prescription information, in an effort to circumvent incompatible computer data systems between hospital and community pharmacies. This study reported a high level of satisfaction with the QR technology from community pharmacists (Lin, Tsai, F., Tsai, W., Wen \& Hu, 2012). Similarly, Marin County, California, has piloted the use of QR codes as a means of patient identification, including such information as an individual's health history, allergies and pertinent information in a QR code that can be scanned by emergency responders when needed. No outcomes or results have been published regarding this application of QR coding ("Fire department tests...", 2012). Two researchers in Venezuela reviewed available technologies for patient identification and concluded that QR coding was the best option to store a large quantity of information, especially when dealing with a low-budget situation (Garcia-Betances \& Huerta, 2012).

One researcher also used QR codes to assist with tool identification for visually impaired individuals, although it is unclear if this study was actually implemented and whether there were resultant outcomes (Al-Khalifa, 2006). Finally, a team of researchers from Mexico developed a prototype application using an Android platform to capture nutritional information designed for a patient population that is tracking food and caloric intake. The team acknowledged the practicality of this application, given the recent proliferation of QR coding on food products, although they did not actually implement their technology with end-users (Vasquez-Briseno, 
Nieto-Hipolito \& Jimenez-Garcia, 2010). Finally, a group of researchers from China have reported success with using $\mathrm{QR}$ codes to represent DNA sequences since the QR stores a larger amount of information than the standard barcode and is amenable to information storage, recognition and retrieval (Liu, et al., 2012). Apart from these studies, no additional evidence of QR code use in health care was located.

\section{Academic integration of $Q R$ coding}

The Doctor of Nursing Practice (DNP) program at XYZ is a post-masters curriculum. DNP students typically enroll in the program part-time and complete the curriculum in 2-4 years while working full time. Students work in a variety of settings, with the majority as practicing clinicians followed by nursing administration. All students participating in the QR integration project were practicing clinicians.

DNP students began integrating the iPad2 into their coursework in 2012. Upon matriculating in the online DNP program, students are issued an iPad2 on loan from XYZ and they are responsible for the expense of downloading any apps that they desire for their iPad2. The purchase and integration of this technology was made possible by HRSA grant XXXXX.

The first DNP course to integrate the iPad2 addressed content regarding population health, program planning and evaluation. Typically, DNP students enroll in this course during their first or second year of the program, depending on how quickly they choose to move through the curriculum. During the semester in question, there were six students enrolled in the course. Faculty and students "eased into" the new technology, using created e-books as texts, using the iPad2 to document community assessments, meeting synchronously using Adobe Connect on the iPad2 and comparing/contrasting and presenting community assessments with the iPad glogster 
app. Faculty also took care to provide patience and extra time for the integration of this new technology.

As the iPad2 was integrated into additional courses, faculty decided to feature tablet technology in a directed, 40-hour practicum experience, nested within the population health course. Course faculty (Author 1) worked with the school's faculty development and technology specialist (Author 2) to develop a project that aimed to reach vulnerable populations, addressed to the goals of the funding grant, incorporated emerging technology and produced a clinically practical and useful product. The resulting 40-hour practicum experience required students to select a health issue of their interest or expertise and develop patient and/or provider resource guides using QR coding. QR coding technology was chosen as the mode of technology for implementation due to the potential for patient/provider individualization, due to the ability of QR codes to capture multi-media and interactive phenomena and the recognition of the increased proliferation and practical application of QR coding. It was posited by the authors that this would be an innovative opportunity to integrate emergent technology into nursing education. Additionally, the QR reading and coding apps were free and easy to download and use.

\section{Practicum implementation}

Resource guides were required to be individualized to the patient or patient population. Incorporating QR coding allowed the inclusion of video, text, simulation, games and/or pertinent local resources. This practicum experience was designed to create clinical education that is interactive, individualized and portable.

At the beginning of the semester, students were directed to download a QR reader and a QR creator application. Suggested applications that were free of cost were provided by faculty, 
but, ultimately, students were able to choose the applications that they preferred. To become familiar with QR technology, students were assigned to survey their surroundings for the presence of QR codes in their everyday lives, practice using the iPad2 to read these codes and get ideas of the different things that $\mathrm{QR}$ codes can do.

For evaluative purposes, students were administered a short baseline survey regarding their extant knowledge, use and possession of technology as well as previous experience and understanding of the QR code at the beginning of the semester. Overall, students indicated a passing familiarity with QR codes. Several students indicated that they had seen "that funny black and white box" previously, but did not know what it was used for. According to baseline survey results, although $50 \%$ of students reported a passing knowledge of what a QR code was, only 33\% had used a QR code in their personal life and 16\% in their professional life prior to this practicum experience. Those students who reported previously using QR codes indicated that they had employed this technology to access a website, access text (ie. nutritional information) and/or access pricing information. No students reported creating a QR code previous to this practicum experience. At baseline, all students reported owning a personal cellular phone equipped with a camera and half of those phones contained a pre-loaded QR reader. One student also reported having a QR creator installed in their personal device, though no students had experience with $\mathrm{QR}$ creation prior to this practicum experience.

At the beginning of the semester, students met individually with the course faculty (Author 1) via telephone to identify their selected topic and overall goals for their practicum projects. This meeting served to clarify expectations, exchange ideas and encourage students' creativity. Although several students expressed some anxiety about using unfamiliar technology, course faculty persevered in encouraging creativity and exploration, reminding students that they 
were doing important work with emerging technology and finding new and significant paths to reach patients and providers. Recognizing the potential for anxiety and misinterpretation of practicum requirements, faculty took care to check in regularly with students throughout the semester regarding their progress with the resource guides. In addition to course faculty, students had access to university IT support for issues concerning the iPad2 hardware.

Throughout the creation of their resource guides, students maintained a practicum hour $\log$ that documented time spent researching peer-reviewed and evidence-based resources. They were encouraged to speak informally with their intended end-user to determine which types of resources would be most useful for them. Ultimately, all students chose to develop patientdirected resource guides. At the end of the semester, students shared their products with each other using the Adobe Connect share screen feature. Final products exhibited a range of creativity and application of the $\mathrm{QR}$ technology, ranging from a simple link to a comprehensive, student-created website addressing organ donation to a general women's health resource pamphlet directed to African American women to a sophisticated handbook regarding the diagnosis and treatment of urinary incontinence. A partial version of this handbook is included as an appendix. All student products were individualized to a particular population or constructed to facilitate individualization. Student-created QR codes linked to resource telephone lines, Youtube clips, pharmaceutical and medical equipment websites and studentcreated websites.

\section{Practicum evaluation}

An evaluation concerning their experience with this project was administered at the end of the semester. Students reported using a variety of QR reader and creator applications and 
each, with the exception of one QR creator was free. Using a Likert scale rating, all students reported that creating and scanning QR codes was easy. Further, 83\% agreed that QR codes would be of benefit to health care providers. Eighty three percent also agreed that QR codes would be of benefit to patients in both the clinical and community settings. All students stated that they were likely to use QR technology in the future. In the course evaluation, one student stated that, “...the practicum $(\mathrm{QR})$ portion helped me become more involved with population health." Students related gratitude to faculty for incorporating creative use of technology, stating, "we learned how to create cool QR Codes etc....I enjoyed the class!...Without it, I would not know... how to create QR codes.” Multiple additional qualitative comments spoke to students' pride in overcoming anxiety regarding creative use technology and integration of technology from the classroom into practice.

Overall, the authors felt that this was a creative and positive way to integrate clinicallyuseful technology in the classroom. Students universally provided positive feedback regarding this practicum experience. Since implementing the first $\mathrm{QR}$-driven practicum, this content was presented at (XYZ University's) annual Faculty Development Day with broader applications introduced. Again, faculty reported excitement over using QR coding in the classroom, with several contacting the authors for further help adapting to their course material. It is (Author 1's) intention to repeat this practicum experience in future semesters, this time encouraging students to stretch their creativity by including additional application of the QR code. Further, (Author 1) will provide an example of previous student work in order to give students a visual representation of possible clinical application of the QR.

\section{Implications}


There are many advantages to using $\mathrm{QR}$ coding in a patient/provider resource document. First, QR codes can encode a great deal of information. If a suggested url is particularly long, there is a risk of the patient or provider mistyping when attempting to access the link. QR codes obviate this issue, linking directly to the desired url upon scanning. Furthermore, the resultant resource tool is portable as long as the patient or provider is equipped with a mobile device that includes a camera. For those patients with limited tactile or visual abilities, scanning a QR code is easier than typing in a small text or url. Last, when linked to resources like pharmaceutical specifications that are constantly updated, this is an excellent way to give just-in-time information to providers and decrease the time in research-to-clinical-implementation.

Employing QR technology also allows for a resource guide that is interactive well beyond a traditional, text-heavy educational pamphlet. Patients and providers can link directly to Youtube or other video clips demonstrating a procedure, explaining or trouble shooting a device or even providing recipes and cooking suggestions for a new diabetic, for example. This technology could also link patients or providers to a real-time database with capabilities to share data regarding chronic disease management (blood sugar readings, daily weights or PT/INR values, for example). All of these are technologies currently available to patients and providers, but enabling them with a QR coded resource document allows them to be in one, centralized location, streamlines the process of accessing multiple resources and precludes the need for a computer to enable access.

This technology, however, does not come without some restrictions. First, it must be ensured that QR codes are linking to mobile websites rather than a full HTML site, as appropriate, in order for the consumer to view a fully compatible website on their mobile device. As with all resource materials, it should also be ensured that the patient or population's specific 
goals are being met. For example, the utility of simply providing a link to the local senior center is limited if the intention is to provide the provider or older adult with information regarding healthy eating and access to meals. Instead, the resource guide creator should link to the senior center's weekly menu and hours for meal distribution. As per standard nursing care, the audience or recipient's individual goals should be honored as the focus of each resource guide. Similarly, resource guides for the provider should be tailored to the medical condition and specific population served. As with all clinical resources, it must be assured that information is peer-reviewed and/or vetted for accuracy.

Finally, a larger issue that has roots in social justice and access to high quality health care regards access to the technology necessary to enable the full use of a QR enhanced resource guide. Although mobile technology and QR resource guides offer the opportunity for more individualized, portable and interactive patient and provider resources, access to smart phone or tablet technology is likely to be limited in the most vulnerable populations.

Overall, we believe that the potential for QR codes as a dynamic and clinically significant technology is strong and will be an important tool in the provision of individualized patient care. This technology is a useful option for creation of appropriate patient and provider resources. Presently, we are conceptualizing appropriate ways to bring this application into undergraduate education. As well, doctoral students are encouraged to expand and possibly copyright their materials in order to bring them forward for implementation in the clinical setting. Ultimately, the authors aim to complete end user and patient outcomes training using a QR enhanced resource guide in the clinical setting. 


\section{References}

Al-Khalifa, H. (2006). Utilizing QR code and mobile phones for blinds and visually impaired people. In K. Meisenberger, J. Klaus, W. Zagler \& A. Karshmer (Eds.) Computers Helping People with Special Needs: Lecture Notes in Computer Science. (p. 1065-1069.) New York: Springer.

Answers to your questions about the QR code. (n.d.) Retrieved July 11, 2013 from http://www.qrcode.com/en/

Bonifacio, V. (2012). QR-coded audio periodic table of the elements: A mobile-learning tool. Journal of Chemical Education 89, 552-554. doi: dx.doi.org/10.1021/ed200541e

Coleman J. (2011). QR codes: What are they and why should you care? Proceedings from Kansas Library Association Conference, 2011: Kansas Library Association, College and University Libraries Section Proceedings. Manhattan, Kansas. doi: http://dx.doi.org/10.4148/culs.v1i0.1355

Diazgranados, M. \& Funk, V. (2013). Utility of QR codes in biological collections. PhytoKeys, 25, 21-34. doi: 10.3897/phytokeys. 25.5175

Fire department tests QR codes for citizen medical data. (2012). Retrieved July 11, 2013 from http://www.govtech.com/health/Fire-Department-Tests-QR-Codes-for-CitizenMedical-Data.html

Garcia-Betances, R. \& Huerta, M. (2012). A review of automatic patient identification options for public health care centers with restricted budgets. Online Journal of Public Health Informatics, 4(1), 1-16.

Gomez, J., Montoro, G., Haya, P., Alaman, X., Alves, S. \& Martinez, M. (2013). Adaptive manuals as assistive technology to support and train people with acquired brain injury in 
their daily life activities. Personal and Ubiquitous Computing, 17, 1117-1126. doi $10.1007 / \mathrm{s} 00779-012-0560-\mathrm{z}$

Lin C. H., Tsai, F. Y., Tsai, W. L., Wen, H. W. \& Hu, M. L. (2012). The feasibility of QRcode prescription in Taiwan. Journal of Clinical Pharmacy and Therapeutics, 37, 643646. doi: 10.1111/j.1365-2710.2012.01358.x

Liu, C., Shi, L., Xu, X., Li, H., Xing, H., Liang, D., Jiang, K., Png, X., Song, J. \& Chen, S. (2012). DNA barcode goes two-dimensions: DNA QR code web server. PLoS ONE, 7(5), e35146.

Vasquez-Briseno, M., Nieto-Hipolito, J. I. \& Jimenez-Garcia, E. (2010). Using QR Codes to Improve Mobile Wellness Applications. International Journal of Computer Science and Network Security, 10(12), 50-53 